\title{
Adsorption of Sodium Cholate on Cationic Dextran Gels: Comparison of Isotherm Binding Models
}

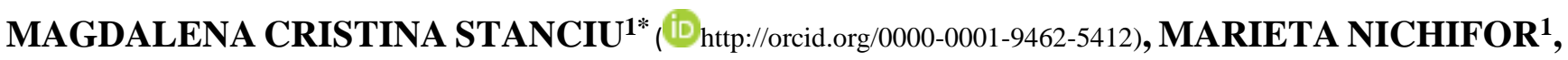 \\ PRISACARU ANCA-IRINA ${ }^{2}$ \\ 1"Petru Poni" Institute of Macromolecular Chemistry, Laboratory of Natural Polymers, Bioactive and Biocompatible \\ Materials, 41A Grigore Ghica Voda Alley, 700487, Iasi, Romania \\ ${ }^{2}$ Fiterman Pharma S.R.L., 127 Pacurari Str., 700544, Iasi, Romania
}

\begin{abstract}
Cationic dextran hydrogels having pendent 51-59 mol\% N-alkyl-N,N-dimethylammonium chloride groups were synthesized and tested as adsorbents for sodium cholate. The bile acid salt sorption by these gels was evaluated by equilibrium analysis in water and $10 \mathrm{mM} \mathrm{NaCl}$ solution. The best adsorption results were obtained with amphiphilic dextran-based gels having two types of pendant ammonium chloride groups with different polarities. Experimental adsorption data for all polymers fitted good with Langmuir, Dubinin-Raduskevich and Temkin models over the entire range of ligand concentrations. The maximum experimental adsorption capacity of dextran sorbents for sodium cholate was in the range $850-1075 \mathrm{mg} / \mathrm{g}$.
\end{abstract}

Keywords: cationic dextran hydrogels, sorption, sodium cholate

\section{Introduction}

Hypercholesteremia is one of the more important factors of risk for cardiovascular disease, a health problem that has an impact on millions of people throughout the world, mainly in the developed countries. Polymeric bile acid sequestrants, BAS, were used for long time as cholesterol lowering agent [1-5]. Generally, BAS are cationic polymeric hydrogels that bind mainly by electrostatic interactions the conjugated bile acid salts in the small intestine and remove them from enterohepatic circulation by excretion. In order to compensate this lowering of bile acids intestinal pool cholesterol is metabolized to bile acids inside the liver, leading to the decrease of plasma cholesterol levels [6]. First (Cholestyramine $^{\circledR}$, Colestipol ${ }^{\circledR}$ )[7-9] and second generation (Colextran ${ }^{\circledR}$, Colesevelam $^{\circledR}$, Colestilan $^{\circledR}$ ) [7,10-13] of commercial BAS have reduced efficacy due to low binding capacity to trihydroxy acids, complexation with fat-soluble vitamins, a decrease in some drugs absorption and GI distress (indigestion, nausea and constipation). Furthermore, the dissociation of the bile acid-BAS complex, when it passes through ileum and colon, requires large doses (2-16 g/day for second generation BAS) to obtain a meaningful therapeutic response. The results are poor patient compliance, high costs and therapeutic failures. Previous studies showed that a better alternative to commercial bile acid sequestrants were aminated polysaccharides due to their improved selectivity for bile acids, biodegradability and better biocompatibility. As polysaccharides were used: $\beta$-cyclodextrin [14], methylans [15], chitosan [16-18], dextran [19-23], microcrystalline cellulose [22,24] and pullulan [22]. Good results were obtained using dextran-based hydrogels bearing one type of pendant quaternary ammonium groups with long-chain alkyl substituents [19, 22-24].

To improve the bile acid adsorption results, we have used in the present work dextran hydrogel microspheres having two types of pendant quaternary ammonium groups, with different alkyl chain length substituents $\left(\mathrm{C}_{2}\right.$ and $\mathrm{C}_{12} / \mathrm{C}_{16}$, respectively) at the nitrogen atom. The goal of this study was the investigation of the influence of dextran hydrogels chemical composition (ratio hydrophilic/hydrophobic groups, total cationic group content) and swelling porosity on sodium cholate adsorption. Different binding isothermal models have been used for this purpose.

$\overline{\text { *email:cstanciu@icmpp.ro }}$ 


\title{
2. Materials and methods
}

\subsection{Materials}

A dextran sample from Leuconostoc mesenteroides with molecular weight $40 \mathrm{kDa}$ was obtained from Sigma. Sodium cholate was supplied by Merck (Darmstadt, Germany). All the other reagents were from Aldrich and used as received.

\subsection{Methods}

\subsubsection{Synthesis of cationic dextran gels}

The synthesis of cationic hydrogels, having the general chemical structure revealed in Scheme 1 and characteristics contained in Table 1, was described in details elsewhere [25-28]. In brief, polysaccharide microparticles were prepared by crosslinking with epichlorohydrin, $\mathrm{ECH}$, and were furthermore reacted with a mixture of a tertiary amine, N,N-dimethyl-N-alkyl amine (alkyl=ethyl, dodecyl or hexadecyl) and $\mathrm{ECH}$ in aqueous solution, for $6 \mathrm{~h}$ at $70^{\circ} \mathrm{C}$. The two distinct pendant ammonium groups, having different alkyl substituents at the nitrogen atom, were attached in steps to dextran backbone. In the first step of amination, groups with dodecyl or hexadecyl were attached, by using dimethyldodecylamine or dimethylhexadecylamine as tertiary amines in the reagent mixture. In the second step of amination, hydrophilic cationic groups were attached by the reaction of the product obtained in the first step and dimethylethylamine-ECH mixture. The resulted gels were purified by filtration and successive washing with water, $\mathrm{HCl} 0.1 \mathrm{~N}$ aqueous solution, water and methanol. Dry hydrogels were obtained as spherical microparticles which were finally sieved, and the fraction with 0.15-0.2 $\mathrm{mm}$ in diameter was used for sorption studies. The degrees of substitution with cationic groups, after first $\left(\mathrm{DS}_{1}\right)$ and second $\left(\mathrm{DS}_{2}\right)$ amination steps, were determined by elemental analysis of nitrogen and by potentiometric titration with $\mathrm{AgNO}_{3}$, and calculated with Eqs. (1) and (2), respectively.

$$
\begin{aligned}
& D S_{1}=\frac{162 \times C l_{1}}{100 \times 35.5-C l_{1} M S_{1}} \times 100, \mathrm{~mol} / 100 \mathrm{GU} \\
& D S_{2}=\left[\frac{X\left(M S_{1}-M S_{2}+\frac{162 \times 100}{D S_{1}}\right)}{100-X \times M S_{2}}-1\right] \times D S_{1}, \mathrm{~mol} / 100 \mathrm{GU}
\end{aligned}
$$

where $\mathrm{X}=\mathrm{Cl}_{t} / 35.5 ; \mathrm{Cl}_{1}$ and $\mathrm{Cl}_{t}$ are the chloride ions contents after first and second quaternization step, respectively; $\mathrm{MS}_{1}$ and $\mathrm{MS}_{2}$ are the molecular weights of the first and the second pendant ammonium group, respectively.

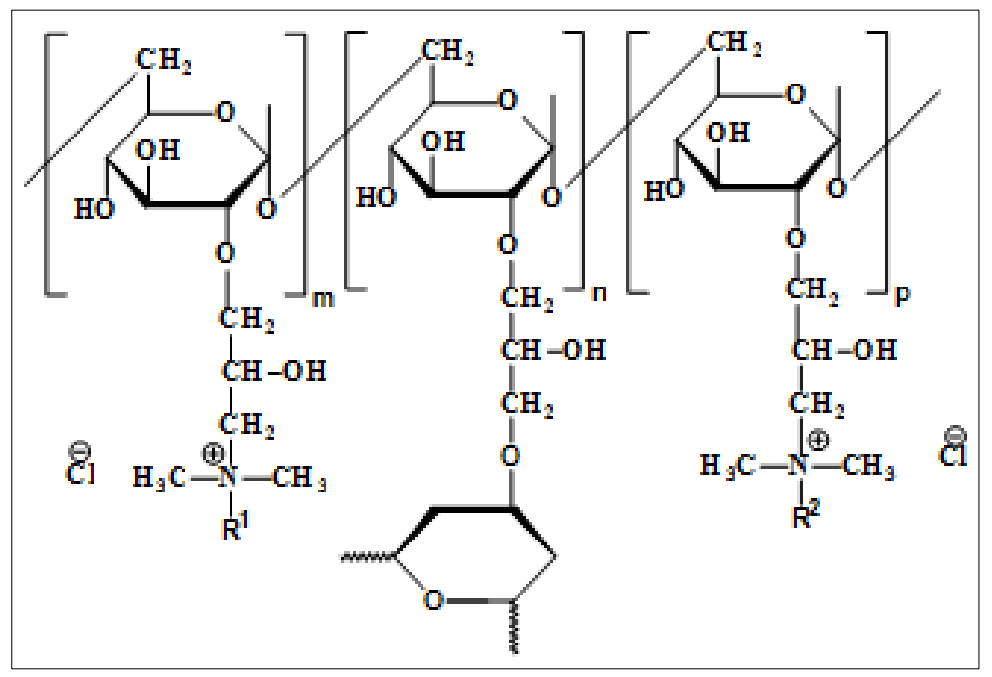

\author{
Scheme 1. Chemical \\ structure of dextran \\ hydrogels \\ $\left(\mathrm{R}_{1}=\right.$ dodecyl $\left(\mathrm{C}_{12}\right)$ or \\ hexadecyl $\left(\mathrm{C}_{16}\right) ; \mathrm{R}_{2}=$ ethyl \\ $\left(\mathrm{C}_{2}\right) ; \mathrm{m}=\mathrm{DS}_{1}$ and $\mathrm{p}=\mathrm{DS}_{2}$
}


Table 1. Chemical composition and swelling porosity of the dextran hydrogels used for sodium cholate sorbtion

\begin{tabular}{|c|c|c|c|c|c|c|}
\hline \multirow{2}{*}{$\begin{array}{c}\text { Hydrogel } \\
\text { code }\end{array}$} & \multicolumn{2}{|c|}{$\mathbf{R}_{1}$} & \multirow{2}{*}{$\begin{array}{c}\mathbf{R}_{2}=\mathbf{C}_{2} \\
D S_{2}, \text { mol\% }\end{array}$} & \multirow{2}{*}{$\begin{array}{l}R_{\mathrm{w}}, \\
\mathrm{g} / \mathrm{g}\end{array}$} & \multicolumn{2}{|c|}{$D S_{t}$} \\
\hline & $\mathbf{C}_{\mathbf{n}}$ & $D S_{1}, \mathrm{~mol} \%$ & & & mol\% & meq/g \\
\hline G1 & - & - & 55.0 & 3.96 & 55.0 & 1.906 \\
\hline G2 & - & - & 55.4 & 15.0 & 55.4 & 2.184 \\
\hline G3 & $\mathrm{C}_{12}$ & 4.4 & 47.3 & 3.10 & 51.7 & 2.040 \\
\hline G4 & $\mathrm{C}_{12}$ & 25 & 38.1 & 4.58 & 52.0 & 2.090 \\
\hline G5 & $\mathrm{C}_{16}$ & 15 & 45.6 & 4.07 & 58.6 & 2.040 \\
\hline
\end{tabular}

\subsubsection{Adsorption experiments}

Sodium cholate sorption experiments were carried out in deionized water or in $10 \mathrm{mM} \mathrm{NaCl}$ solution. Dry gel microspheres $(10 \mathrm{mg})$ were weighted in $20 \mathrm{~mL}$ vials, suspended in distilled water, gently stirred for $1 \mathrm{~h}$ and then mixed with bile acid salt stock solution $(5 \mathrm{mM}$ in deionized water or in $10 \mathrm{mM} \mathrm{NaCl}$ solution) in the amount required to obtain the wanted initial NaCA concentration (0.1-3 $\mathrm{mM})$ in the mixture and a final mixture volume of $10 \mathrm{~mL}$. The contact time to aquire the system equilibration was $24 \mathrm{~h}$. Then, the suspensions were filtered on sintered glass crucible, and the clear filtrates were analyzed by UV $(378 \mathrm{~nm})$ (spectrophotometer Specord 200 Plus-Analytic Jena) for their content in cholate (equilibrium concentration, $\mathrm{C}_{\mathrm{eq}}, \mathrm{mM}$ ) after treatment with sulfuric acid $42 \mathrm{vol} \%$, according to a method described earlier [29]. The bile acid salt retained by the sorbent at equilibrium, $q_{e}(\mathrm{mmol} / \mathrm{g})$, was calculated with Eq. (3)

$$
q_{e}=\frac{\left(C_{i}-C_{e q}\right)}{100 \times m}, \mathrm{mmol} / \mathrm{g}
$$

where $C_{i}$ is the initial bile acid salt concentration, $C_{e q}$ is the residual $\mathrm{NaCA}$ concentration at equilibrium, respectively, in $\mathrm{mM}$, and $\mathrm{m}$ is the mass, in $\mathrm{g}$, of dry hydrogel. Each sorption experiment was performed in triplicate.

\section{Results and discussions}

\subsection{Hydrogel synthesis}

An efficient BAS must have structural characteristics which enable an enhancement of hydrogel$\mathrm{NaCA}$ interactions. Thus, a high percent in strong basic quaternary ammonium groups facilitates the binding of oppositely charged $\mathrm{NaCA}$ by electrostatic interactions and the occurrence of hydrophobic moieties allows additional interaction forces (hydrophobic associations) between adsorbent and ligand. Also, the hydrogels must have a swelling porosity which facilitate the access of sodium cholate molecules inside the pores of adsorbent microspheres. A high cationic charge density with a suitable hydrophilic/hydrophobic balance was obtained by the existence of two types of pendant quaternary ammonium groups with different polarities (Scheme 1). The attachment of the two kind of pendant groups in different steps of polymers' synthesis enabled a rigorous control of each group-content in the final polymer. There is no porosity in the dry state of the gels but the penetration of water molecules inside the hydrogels determines the gel network extension with the appearance of the pores. The swelling porosity of the hydrogels was controlled by dextran crosslinking degree (ECH used in the crosslinking step), the total charge density and content in hydrophobic groups.

\subsection{Adsorption isotherms}

Adsorption isotherms provide the relationship between the concentration of the sorbate on the solid phase and its concentration in the liquid phase under equilibrium conditions and can offer helpful information about maximum adsorption capacity and potential interactions between adsorbate and sorbent. A quantitative comparison of adsorbtion performances obtained with different sorbents is 
possible using adsorption isotherms [30].

The isotherms for binding of $\mathrm{NaCA}$ in water and $10 \mathrm{mM} \mathrm{NaCl}$ solution by dextran hydrogels are showed in Figure 1.

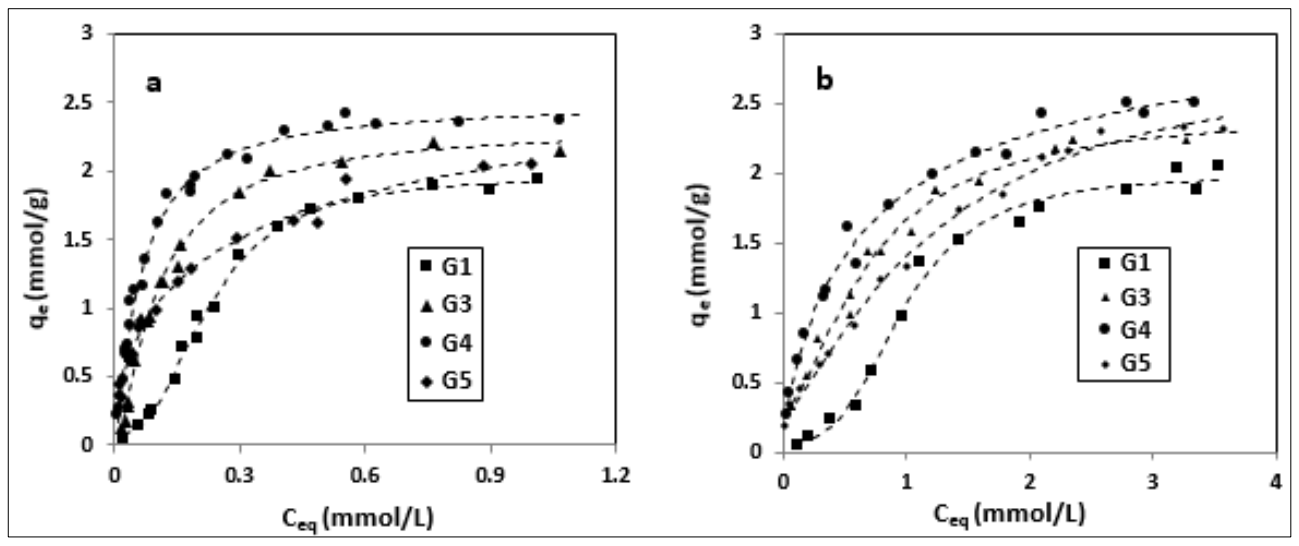

Figure 1. Adsorbtion isotherms of sodium cholate on dextran hydrogels in water (a) and $10 \mathrm{mM} \mathrm{NaCl}$ solution (b)

The isotherms are plotted as the amount of adsorbed bile acid salt $\left(q_{e}\right)$ versus free bile acid concentration at equilibrium $\left(C_{e q}\right)$. The binding of the bile acid salt on the hydrophilic dextran gel (G1) was mainly electrostatic, and the binding process was cooperative, as the sigmoidal shape of binding isotherm shows (Figure 1a). The cooperativity is due to the hydrophobic interaction between one bound and one free ligand molecule which promoted an acceleration of the electrostatic binding.

The amount of sodium cholate adsorbed at equilibrium was higher for amphiphilic hydrogels (G3G5) compared to the hydrophilic gel G1 due to the existence of both ionic and hydrophobic interactions between sorbate and adsorbent. The increase of $\mathrm{DS}_{1}$ values for hydrophobically modified cationic gels determined the augmentation of $\mathrm{NaCA}$ amount retained at equilibrium (Figure 1a). The hydrophobic interactions between amphiphilic polyelectrolytes and bile acid salt prevailed over the electrostatic ones and aggregation occurred mostly through mixed micelle formation. It is known that bile acid salts can form mixed micelles with fatty acids, cholesterol, lecithin through hydrophobic interactions [25] or with surfactants like alkyltrimethylammonium halide via ionic interactions [31].

The hyperbolic shape of the binding isotherms for G3-G5 pointed out a low binding cooperativity, which can be attributed to the fact that the formation of mixed micelles by the interaction between very disimetric hydrophobic moieties of the sorbate (steroid) and sorbent pendent group (alkyl) is more favorable than the interaction between two bulky sorbate molecules. In the case of the hydrogel having pendant cetyl groups (G5), the amount of bile acid salt adsorbed at equilibrium was lower than that of the hydrogels with pendant dodecyl groups (G3, G4) due to the steric hindrance between the steroid nucleus of sodium cholate and the bulky pendant alkyl groups of the cross-linked polymer (Figure 1a).

An accentuation of the sigmoidal shape of the binding isotherm for G1 could be observed in $10 \mathrm{mM}$ $\mathrm{NaCl}$ solution while the hyperbolicity of the binding isotherms for G3-G5 decreased (Figure 1b). Thus, it seemed that the ionic strength had a greater effect on the self-aggregation of bile salts molecules inside the hydrophilic gels than on the formation of mixed micelles between the sodium cholate and pendant hydrophobic groups of polymer.

The experimental data were correlated with theoretical or empirical equations supplied by isotherm models. Various two-parameter model sorption isotherms such as Langmuir, Freundlich, DubininRaduskevich (D-R) and Temkin were were chosen to assess the equilibrium characteristics of the adsorption processes. The parameters of the isotherm equations were calculated by linear regression analysis. 
Langmuir adsorption model [32] fits in for ideal sorption that happens on homogeneous surfaces and implies monolayer adsorption while Freundlich isotherm [33] is applicable for non-ideal sorption that occur on heterogeneous surfaces and implies multilayer adsorption. Dubinin-Radushkevich isotherm [34] is generally applied to reveal the adsorption mechanism [35] with a Gaussian distribution of energy onto a heterogeneous surface [36] whilst Temkin isotherm model [37, 38] takes into account the existence of sorbate-adsorbate interactions assuming that the heat of adsorption of all molecules in the layer decreases linearly as a result of increase surface coverage. The linear forms for these binding isotherms models are given by Eqs. (4-7).

$$
\begin{aligned}
\frac{C_{e q}}{q_{e}} & =\frac{C_{e q}}{Q_{L}}+\frac{1}{K_{L} Q_{L}} \\
\log q_{e} & =\log K_{F}+\frac{1}{n} \log C_{e q} \\
\ln q_{e} & =\ln Q_{R D}-\beta \varepsilon^{2} \\
q_{e} & =\frac{R T}{\Delta Q} \ln K_{T}+\frac{R T}{\Delta Q} \ln C_{e q}
\end{aligned}
$$

where $q_{e}(\mathrm{mmol} / \mathrm{g})$ is the experimental bile acid salt amount adsorbed at equilibrium, $C_{e q}$ is concentration of sorbate in the bulk solution at equilibrium (mmol/g), $Q_{L}$ and $Q_{D R}(\mathrm{mmol} / \mathrm{g})$ are calculated maximum adsorbent capacities, $K_{L}(\mathrm{~L} / \mathrm{mmol}), K_{F}(\mathrm{mmol} / \mathrm{g})$ and $K_{T}(\mathrm{~L} / \mathrm{mmol})$ are Langmuir, Freundlich and Temkin equilibrium constants, $n_{F}$ is the heterogeneity factor (Freundlich coefficient), $\Delta \mathrm{Q}(\mathrm{kJ} / \mathrm{mol})$ is variation of the sorption energy. $\beta\left(\mathrm{mol}^{2} / \mathrm{J}^{2}\right)$ is a constant related to the mean free energy per molecule of adsorbate for removing from its location in the sorption space to the infinity in the solution and $\varepsilon$ is Polanyi potential, which can be calculated by the relationship:

$$
\varepsilon=R \operatorname{Rln}\left(1+\frac{1}{C_{e q}}\right)
$$

where $\mathrm{R}$ is the universal gas constant $(8.314 \mathrm{~J} / \mathrm{mol} \mathrm{K})$ and $\mathrm{T}$ is the solution temperature $(\mathrm{K})$.

A good concordance between theoretical data obtained using Eqs. (4-8) and the experimental ones should provide straight lines. The slope and intercept of the graphs afforded the determination of the parameter values characteristic to each isotherm model. The values of parameters determined from these plots are showed in Tables 2 and 3. Comparison of the linear regression correlation coefficient $R^{2}$ values resulted by using different model isotherms showed that good fits were obtained with Langmuir, D-R and Temkin models, for which $R^{2} \geq 0.951$, both in water and $\mathrm{NaCl}$ solution. This finding was supported by the good agreement between experimental maximum adsorption capacities and the calculated $Q_{L}$ and $Q_{D R}$ values (Tables 2 and 3). Therefore, the parameters calculated with these models can be used to evaluate the adsorption mechanism. For example, the good fitting of the experimental data to Langmuir model confirmed the homogeneous monolayer adsorbtion of NaCA by dextran-based hydrogels, what was also observed for other bile acid-sorbent systems [39-42].
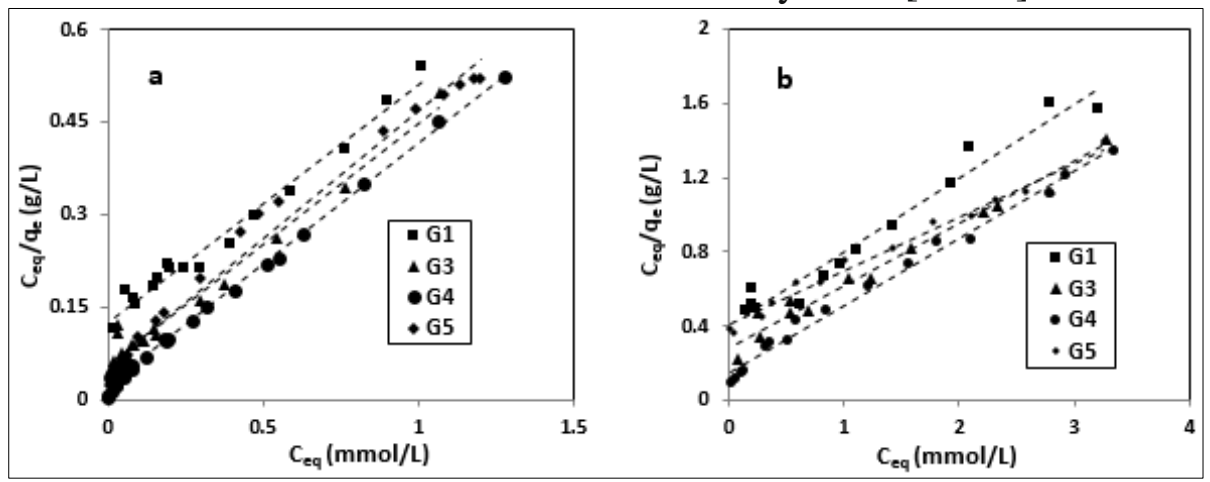

Figure 2. Linear forms of isotherms for adsorption of $\mathrm{NaCA}$ in water (a) and $10 \mathrm{mM}$ $\mathrm{NaCl}$ solution (b)on dextran hydrogels calculated according to Langmuir model 
Langmuir constant values $\left(K_{L}\right)$ are associated to the affinity between bile acid salt and gels. Its values increased in the order: G1 $<\mathrm{G} 2<\mathrm{G} 3<\mathrm{G} 5<\mathrm{G} 4$. It could be seen that NaCA adsorption on cationic dextran gels increased mainly with the increase of swelling porosity, the pendant alkyl chain length and total cationic group content. A several times increase of water uptake for cationic gel G2 compared to G1 improved the adsorbtion process due to the increased number of ligand molecules that could penetrate into the polymeric microspheres through their pores (Table 2).

Table 2. Parameters calculated from linear regression analysis of experimental data with model isotherms, for sodium cholate adsorption in water

\begin{tabular}{|c|c|c|c|c|c|}
\hline $\begin{array}{c}\text { Hydrogel } \\
\text { code }\end{array}$ & G1 & G2 & G3 & G4 & G5 \\
\hline$Q_{\text {exp }}, \mathrm{mmol} / \mathrm{g}$ & 1.96 & 2.38 & 2.21 & 2.44 & 2.094 \\
\hline$Q_{e x p}, \mathrm{mg} / \mathrm{g}$ & 843.97 & 1024.82 & 951.62 & 1050.66 & 901.67 \\
\hline$Q_{\text {exp }}, \mathrm{mmol} / \mathrm{meqN}^{+}$ & 1.028 & 1.089 & 1.08 & 1.16 & 1.01 \\
\hline \multicolumn{6}{|l|}{ Langmuir } \\
\hline$K_{\mathrm{L}}, \mathrm{L} / \mathrm{mmol}$ & 2.411 & 3.76 & 7.267 & 16.018 & 10.286 \\
\hline $\begin{array}{c}Q_{\mathrm{L}}, \mathrm{mmol} / \mathrm{g} \\
(\mathrm{mg} / \mathrm{g})\end{array}$ & $\begin{array}{c}2.187 \\
(941.72) \\
\end{array}$ & $\begin{array}{c}2.58 \\
(1110.94)\end{array}$ & $\begin{array}{c}2.372 \\
(1021.38) \\
\end{array}$ & $\begin{array}{c}2.5 \\
(1076.5) \\
\end{array}$ & $\begin{array}{c}2.136 \\
(919.761) \\
\end{array}$ \\
\hline$Q^{*}, \mathrm{mmol} / \mathrm{meqN}$ & 1.14 & 1.18 & 1.16 & 1.13 & 1.03 \\
\hline$R_{L}^{a}$ & $0.574-0.073$ & $0.583-0.0107$ & $0.544-0.056$ & $0.356-0.035$ & $0.469-0.055$ \\
\hline$R^{2}$ & 0.987 & 0.973 & 0.985 & 0.997 & 0.983 \\
\hline \multicolumn{6}{|l|}{ Freundlich } \\
\hline$K_{\mathrm{F}}, \mathrm{mmol} / \mathrm{g}$ & 1.55 & 1.88 & 2.64 & 2.92 & 2.21 \\
\hline $1 / n_{\mathrm{F}}$ & 0.997 & 0.602 & 0.507 & 0.416 & 0.388 \\
\hline$R^{2}$ & 0.912 & 0.906 & 0.908 & 0.907 & 0.96 \\
\hline \multicolumn{6}{|c|}{ Dubinin-Raduskevich } \\
\hline$Q_{D R}, \mathrm{mmol} / \mathrm{g}$ & 2.188 & 2.200 & 2.361 & 2.570 & 2.052 \\
\hline$\beta, \mathrm{mmol}^{2} / \mathrm{J}^{2}$ & 4.761 & 4.104 & 2.104 & 1.709 & 1.194 \\
\hline$E, \mathrm{~kJ} / \mathrm{mol}$ & 9.14 & 9.17 & 4.874 & 6.90 & 6.471 \\
\hline$R^{2}$ & 0.963 & 0.992 & 0.98 & 0.97 & 0.963 \\
\hline \multicolumn{6}{|l|}{ Temkin } \\
\hline$K_{0}, \mathrm{~L} / \mathrm{mmol}$ & 23.13 & 24.70 & 68.86 & 357.149 & 227.443 \\
\hline$\Delta Q, \mathrm{KJ} / \mathrm{mol}$ & 19.236 & 19.130 & 4.386 & 5.896 & 7.244 \\
\hline$R^{2}$ & 0.964 & 0.982 & 0.966 & 0.946 & 0.965 \\
\hline
\end{tabular}

${ }^{a}$ For $C_{i}$ in the range of $0.1-3 \mathrm{mM}$

The maximum value of $K_{L}$ was obtained for G4 due to its highest $\mathrm{DS}_{1}$ value with pendant ammonium groups with dodecyl which amplified the hydrophobic and electrostatic interactions between bile acid salt and hydrogel. Langmuir constant value decreased for hydrogel G5 perhaps due to the steric hindrance existing between bulky steroid nucleus of the ligand and pendant cetyl groups of the sorbent.

Using Langmuir model was also determined: $Q^{*}$, representing mmols of adsorbed NaCA per meq cationic group of gel which evaluated the number of sodium cholate molecules bound by one cationic site. All $Q^{*}$ values were higher than 1 both in water and $10 \mathrm{mM} \mathrm{NaCl}$ solution showing the contribution of hydrophobic interactions besides the electrostatic ones.

Another parameter of Langmuir equation is $R_{L}$, a dimensionless separation factor described by the equation:

$$
R_{L}=\frac{1}{1+K_{L} C_{i}}
$$


$R_{L}$ is dependent on initial concentration of adsorbate, $C_{i}$, and its values indicated the efficiency of the adsorption process. So, adsorption is unfavourable when $R_{L}>1$, linear when $R_{L}=1$, favourable when 0 $<R_{L}<1$, and irreversible when $R_{L}=0$.

Table 3. Parameters calculated from linear regression analysis of experimental data with model isotherms, for $\mathrm{NaCA}$ adsorption in $10 \mathrm{mM} \mathrm{NaCl}$ solution

\begin{tabular}{|c|c|c|c|c|}
\hline $\begin{array}{c}\text { Hydrogel } \\
\text { code }\end{array}$ & G1 & G3 & G4 & G5 \\
\hline$Q_{\text {exp }}, \mathrm{mmol} / \mathrm{g}$ & 2.092 & 2.333 & 2.496 & 2.115 \\
\hline$Q_{\text {exp }}, \mathrm{mg} / \mathrm{g}$ & 900.81 & 1004.58 & 1074.77 & 910.71 \\
\hline$Q_{\text {exp }}, \mathrm{mmol} / \mathrm{meqN}{ }^{+}$ & 1.098 & 1.143 & 1.194 & 1.019 \\
\hline Langmuir & 3.577 & 7.121 & 16.125 & 12.41 \\
\hline$K_{\mathrm{L}}, \mathrm{L} / \mathrm{mmol}$ & 2.258 & 2.421 & 2.552 & 2.25 \\
\hline $\begin{array}{c}Q_{\mathrm{L}}, \mathrm{mmol} / \mathrm{g} \\
(\mathrm{mg} / \mathrm{g})\end{array}$ & $(936.16)$ & $(1003.74)$ & $(1058.05)$ & $(968.85)$ \\
\hline$Q^{*}, \mathrm{mmol} / \mathrm{meqN}^{+}$ & 1.184 & 1.186 & 1.220 & 1.084 \\
\hline$R_{L}{ }^{2}$ & $0.63-0.14$ & $0.872-0.16$ & $0.584-$ & $0.76-0.15$ \\
\hline$R^{2}$ & 0.951 & 0.98 & 0.972 & 0.98 \\
\hline Freundlich & 1.76 & 2.01 & 2.23 & 2.07 \\
\hline$K_{\mathrm{F}, \mathrm{mmol} / \mathrm{g}}$ & 0.957 & 0.653 & 0.427 & 0.469 \\
\hline $1 / n_{\mathrm{F}}$ & 0.94 & 0.94 & 0.966 & 0.98 \\
\hline$R^{2}$ & 1.905 & 2.225 & 2.286 & 2.393 \\
\hline$Q_{D R}, \mathrm{mmol} / \mathrm{g}$ & 8.96 & 8.343 & 2.64 & 12.71 \\
\hline$\beta, \mathrm{mmol} / \mathrm{J}^{2}$ & 8.06 & 3.27 & 4.40 & 4.56 \\
\hline$E, \mathrm{~kJ} / \mathrm{mol}$ & 0.983 & 0.957 & 0.977 & 0.96 \\
\hline$R^{2}$ & 4.89 & 15.96 & 44.06 & 30.75 \\
\hline Temkin & 18.55 & 4.326 & 5.019 & 5.34 \\
\hline$K_{0}, \mathrm{~L} / \mathrm{mmol}$ & 0.99 & 0.94 & 0.96 & 0.98 \\
\hline$\Delta Q, \mathrm{KJ} / \mathrm{mol}$ & $R^{2}$ & \multicolumn{5}{|l}{} \\
\hline
\end{tabular}

${ }^{a}$ For $C_{i}$ in the range of $0.1-3 \mathrm{mM}$

$R_{L}<1$ for all dextran gels and over the entire range of initial sodium cholate concentrations which showed a favorable adsorption process. This parameter decreases asymptotically with $C_{i}$ and tends to zero at high polymer concentrations (Figure 3 ).
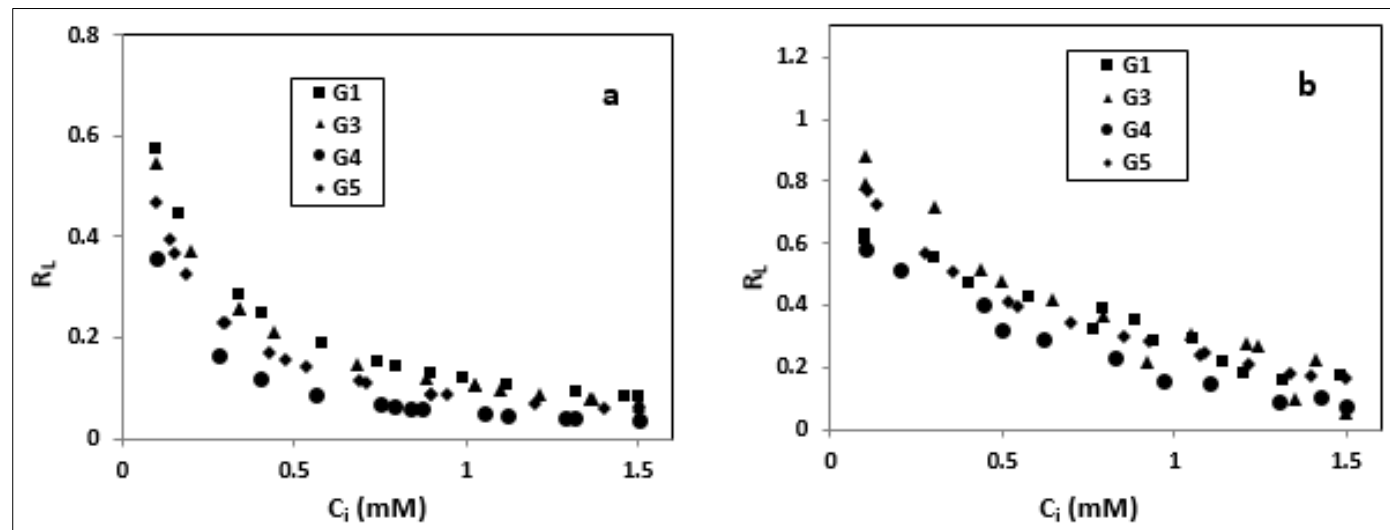

Figure 3.

Variation of RL with bile acid initial concentration in water (a) and $\mathrm{NaCl}$ solution (b) 
Dubinin-Radushkevich model, which matched well for other bile acid salt-adsorbent systems [43, 44], allows calculation the mean free energy of adsorption per molecule of adsorbate, $E(\mathrm{~kJ} / \mathrm{mol})(\mathrm{Eq}$. 10). This parameter is useful to differentiate between the physical and chemical adsorption. When the adsorption energy is less than $8 \mathrm{~kJ} / \mathrm{mol}$, the sorption process is dominated by physical forces, if $E$ is between 8 and $16 \mathrm{~kJ} / \mathrm{mol}$, the adsorption is controlled by ion exchange mechanism and when the value of $E$ is greater than $16 \mathrm{~kJ} / \mathrm{mol}$, the process is governed by chemisorption.

$$
E=\frac{1}{\sqrt{2 \beta}}
$$
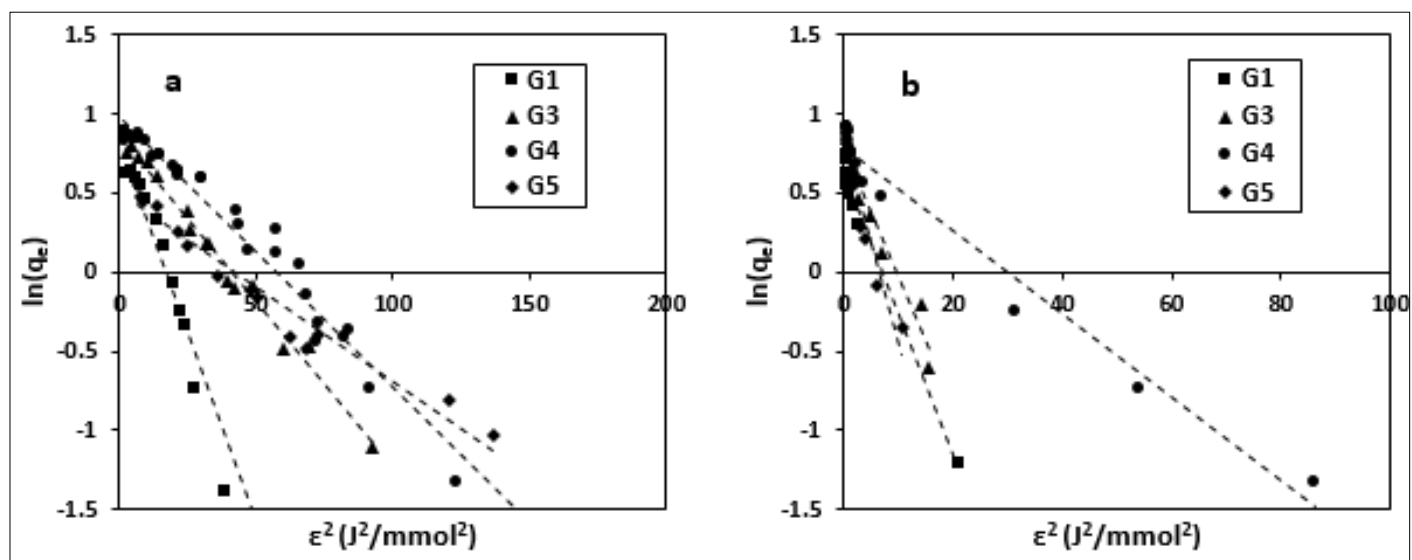

Figure 4. Linear forms of isotherms for adsorption of sodium cholate in water (a) and $10 \mathrm{mM} \mathrm{NaCl}$ solution (b) on polymers calculated according to Dubinin-Radushkevich model

According to the data included in Tables 2 and 3, $E$ is lower than $8 \mathrm{~kJ} / \mathrm{mol}$ for cationic amphiphilic gels (G3-G5) and higher than this value for cationic hydrogels (G1, G2). That implies an essential involvement of ion exchange (G1, G2) and physical forces (G3-G5), respectively to the mechanism of adsorption.

The good fit of the Temkin isotherm model demonstrated that adsorption was characterized by a uniform distribution of binding energies, up to a maximum binding energy [30]. There are many systems bile acid-sorbent where Temkin isotherm fitted good [40,41,43-46]. $\Delta \mathrm{Q}=(-\Delta \mathrm{H})$ was positive for all the studied polymers, which indicated that the adsorption process was exothermic. The values of $\Delta \mathrm{Q}$ were higher for cationic gels G1 and G2 compared to cationic amphiphilic polymers G3-G5 due to the involvement of ion-exchange to the adsorption mechanism in the first case and physical forces in the second case. $\Delta \mathrm{Q}$ values increased with the augmentation of DS values (Tables 2 and 3).

Freundlich model fitted less well to adsorption data both in water and $10 \mathrm{mM} \mathrm{NaCl}$ solution, as 0.91 $<R^{2}<0.96$, and Freundlich constant values, $K_{F}$, which measure the maximum sorption capacity of the adsorbent, deviate from $Q_{\exp }$ values (Tables 2 and 3). For another systems bile acid-sorbent, Freundlich isotherm fitted very well $[41,42,47,48]$. The values calculated for Freundlich coefficient, $n_{F}$, a measure of both adsorption intensity and heterogeneity of the adsorbate sites, were in the range $0<1 / n_{F}<1$, which showed the favorable sorption process for all hydrogels used [31,41,42,47,48]. Freundlich coefficient values were close to 1 for cationic hydrogel G1 which indicated a cooperative adsorption. 

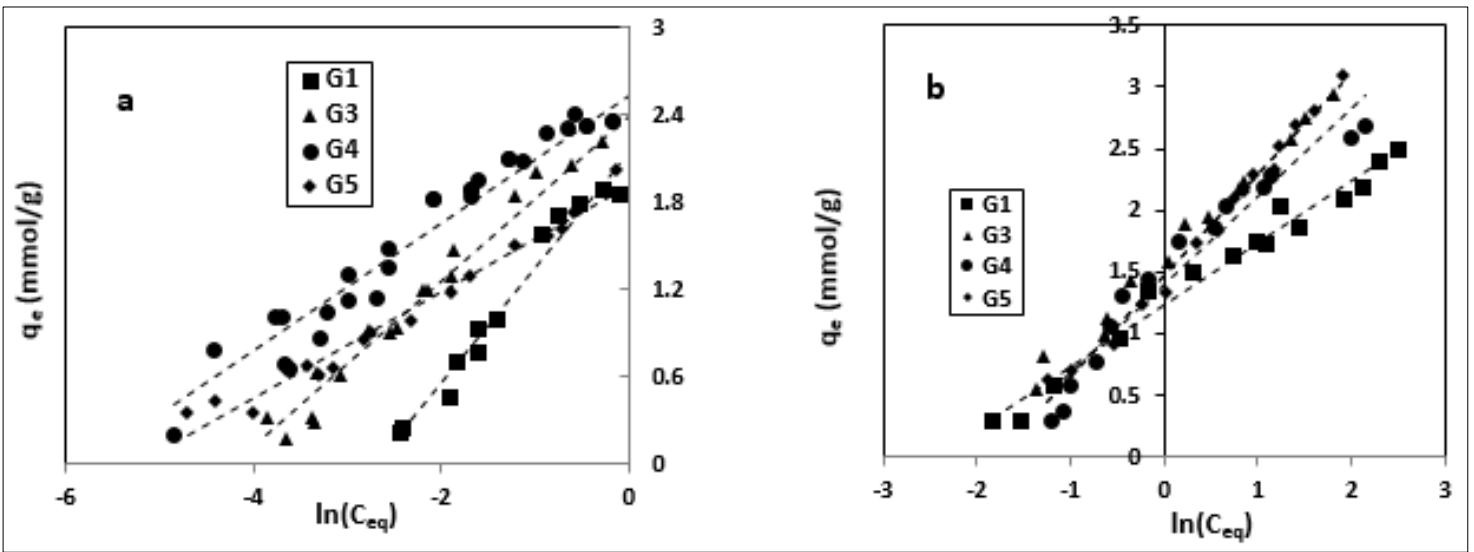

Figure 5. Linear forms of isotherms for adsorption of $\mathrm{NaCA}$ in water (a) and $10 \mathrm{mM} \mathrm{NaCl}$ solution (b) on dextran gels calculated according to Temkin model

The addition of $\mathrm{NaCl}$ in the adsorption medium has no influence of the general adsorption mechanism and the variation of the calculated parameters with sorbent properties is similar to that found in water. It is worth mentioning that the maximum sorption capacity does not decrease in the presence of competing ions $\left(\mathrm{Cl}^{-}\right)$, showing a good selectivity for bile acids of the studies adsorbents.

The maximum experimental adsorption capacity of dextran-based hydrogels for NaCA (850-1075 $\mathrm{mg} / \mathrm{g}$ ) was higher than that found for the same ligand when adsorbed on aminated polysaccharides or resins $[40,41,45,49,50]$ but lower when compared with hydrogels based on aminated synthetic (co)polymers [51,52] (Table 5). However, the later have a much higher content in quaternary ammonium groups.

Table 5. Comparison of maximum experimental adsorption capacity of $\mathrm{NaCA}$ by different sorbents

\begin{tabular}{|l|c|c|}
\hline \multicolumn{1}{|c|}{ Adsorbent } & Q $\exp , \mathbf{m g} / \mathbf{g}$ & References \\
\hline Cationic microfibrillated cellulose & 249.2 & {$[41]$} \\
\hline Cationic amphiphilic microfibrillated cellulose & 79.3 & {$[45]$} \\
\hline Amino-functionalized celluloseby hyperbranched polyethylenimine & 569.7 & {$[40]$} \\
\hline Polyacrylamide resin with pendant quaternary ammonium groups & 903 & {$[49]$} \\
\hline N-Octadecylpectinamide & 817 & {$[50]$} \\
\hline $\begin{array}{l}\text { Poly((3-acrylamidopropyl)trimethylammonium } \\
\text { chloride)-co-poly(2-hydroxyethyl acrylate))-based hydrogel }\end{array}$ & 1553 & {$[51]$} \\
\hline Poly((3-acrylamidopropyl)trimethylammonium chloride) -based hydrogel & 1778 & {$[52]$} \\
\hline \begin{tabular}{l} 
Dextran-based hydrogels \\
\hline
\end{tabular} & $850-1075$ & This work \\
\hline
\end{tabular}

\section{Conclusions}

Study of the sodium cholate sorption on cationic dextran hydrogel microspheres carrying pendant $\mathrm{N}$ alkyl-N,N-dimethylammonium chloride groups was quantitatively evaluated by equilibrium studies in water and $10 \mathrm{mM} \mathrm{NaCl}$ solution. The obtained results showed a clear enhancement of binding process 
for cationic amphiphilic gels due to the contribution of hydrophobic interactions besides the electrostatic ones. Langmuir, Dubinin-Raduskevich and Temkin were the binding isotherm models who gave a good fit of the experimental adsorption data. The maximum experimental adsorption capacity of dextranbased gels for sodium cholate was higher compared to other aminated polysaccharide-based sorbents. All these results recommend the cationic amphiphilic dextran hydrogels as new and more efficient bile acid sorbents.

\section{Acknowledgments}

This work was financially supported by the European Social Fund for Regional Development, Competitiveness Operational Program Axis 1-Project "Petru Poni Institute of Macromolecular Chemistry-Interdisciplinary Pol for Smart Specialization through Research and Innovation and Technology Transfer in Bio(nano)polymeric Materials and (Eco)Technology," InoMatPol (ID P_36_570, Contract 142/10.10.2016, cod MySMIS: 107464).

\section{References}

1. MENDONCA, P., SERRA, A., SILVA, C., SIMOES, S., COELHO, J., Polymeric bile acid sequestrants-Synthesis using conventional methods and new approaches based on "controlled"/living radical polymerization, Prog. Polym. Sci., 38, 2013, 445-461.

2. GORE, M.A., KULKARNI, M.G.K., Bile acid sequestrants and process for preparation therefor, 2007, US Patent No. 0122375.

3. MANDEVILLE, W.H., HOLMES-FARLEY, S.R., Process for removing bile salts from a patient and alkylated compositions therefor, 1995, WO No. 95/34585.

4. HOLMES-FARLEY, S.R., MANDEVILLE, W.H., BURKE, S.K., GOLDBERG, D.I., Method for treating hypercholesterolemia with polyallylamine polymers, 2002, US Patent No. 6,423,754.

5. HOLMES-FARLEY, S.R., DHAL, P.K., PETERSEN, J.S., Poly-(diallylamine)-based bile acid sequestrants, 2006, US Patent No. 7,125,547.

6. INSULL, W., Clinical utility of bile acid sequestrants in the treatmentof dyslipidemia: a scientific review, South. Med. J., 99, 2006, 257-273.

7. MANDEVILLE, W.H., GOLDBERG, D.I., The sequestration of bile acids, a non-absorbed method for cholesterol reduction. A review, Curr. Pharm. Des., 3, 1997, 15-26.

8. HARROLD, M., Antihyperlipoproteinemics and inhibitors of cholesterol biosynthesis, In: Lemke, T.L., Williams, D.A., (Eds), Foye's principles of medicinal chemistry, 6th ed. Philadelphia: Lippincott Williams \& Wilkins, 2007, 797-819.

9. BENSON, G.M., HAYNES, C., BLANCHARD, S., ELLIS, D., In vitro studies to investigate the reasons for the low potency of cholestyramine and colestipol, J. Pharm. Sci., 82, 1993, 80-86.

10. HUVAL, C.C., HOLMES-FARLEY, S.R., MANDEVILLE, W.H., SACCHIERO, R., DHAL, P.K., Syntheses of hydrophobically modified cationic hydrogels by copolymerization of alkyl substituted diallylamine monomers and their use as bile acid sequestrants, Eur. Polym. J., 40, 2004, 693-701.

11. POLLEX, R.L., JOY, T.R., HEGELE, R.A., Emerging antidyslipidemic drugs, Expert Opin. Emer. Drugs, 13, 2008, 363-381.

12. HONDA, Y, NAKANO, M., Studies on adsorption characteristicsof bile acids and methotrexate to a new type of anionexchangeresin, colestimide, Chem. Pharm. Bull., 48, 2000, 978-981.

13. DAVIDSON, M.H., DILLON, M.A., GORDON, B., JONES, P., SAMUELS, J., WEISS, S., ISAACSOHN, J., TOTH, P., BURKE, S.K., Colesevelam hydrochloride (cholestagel): a new, potent bile acid sequestrant associated with a low incidence of gastrointestinal side effects, Arch. Intern. Med., 159,1999, 1893-900.

14. BAILlE, W.E., HUANG, W.Q., NICHIFOR, M., ZHU, X.X., Functionalized betacyclodextrin 
polymers for the sorption of bile salts, J. Macromol. Sci. A, 37, 2000, 77-90.

15. LEE, J.K., KIM, S.Y., KIM, S.U., KIM, J.H., Synthesis of cationic polysaccharide derivatives and their hypocholesterolaemic capacity, Biotechnol. Appl. Biochem., 35, 2002, 181-189.

16. IKEDA, I., SUGANO, M., YOSHIDA, K., SASAKI, E., IWAMOTO, Y., HATANO, K., Effects of chitosan hydrolyzates on lipid absorption and on serum and liver lipid concentration in rats, J. Agric. Food Chem., 41, 1993, 431-435.

17. LEE, J.K., KIM, S.U., KIM, J.H., Modification of chitosan to improve its hypocholesterolemic capacity, Biosci. Biotechnol. Biochem., 63, 1999, 833-839.

18. MURATA, Y., KODOMA, Y., HIRAI, D., KOFUGI, K., KAWASHIMA, S., Properties of an oral preparation containing a chitosan salt, Molecules, 14, 2009, 755-6276.

19. NICHIFOR, M., ZHU, X.X., BAILLE, W., CRISTEA, D., CARPOV, A., Bile acid sequestrants based on cationic dextran hydrogel microspheres. 2. Influence of the length of alkyl substituents at the amino groups of the sorbents on the sorption of bile salts, J. Pharm. Sci., 90, 2001, 681-689.

20. NICHIFOR, M., ZHU, XX, CRISTEA, D., CARPOV, A., Interaction of hydrophobically modified cationic dextran hydrogels with biological surfactants, J. Phys. Chem. B, 105, 2001, 2314-2321.

21. NICHIFOR, M., CRISTEA, D., CARPOV, A., Sodium cholate sorption on cationic dextran hydrogel microspheres. 1. Influence of the chemical structure of functional groups, Int. J. Biol. Macromol., 28, $2000,15-21$.

22. NICHIFOR, M., CRISTEA, D., MOCANU, G., CARPOV, A., Aminated polysaccharides as bile acid sorbents: in vitro study, J. Biomat. Sci. Polym. Ed., 9, 1998, 519-534.

23. NECHIFOR, M., FILIP, C., PADURARU, I., NICHIFOR, M., CARPOV, A., Synthesis and pharmacological action of some cholestyramine analogs. In: Ottenbrite, R.M., Chiellini, E., (Eds), Polymers in medicine: Biomedical and pharmaceutical applications, Lancaster: Technomic Publishing Company, 1992, 145-165.

24. NICHIFOR, M., CRISTEA-CSERGO, D., CARPOV, A., In vitro bile acid binding on aminated microcrystalline cellulose, STP Pharma Sci., 44, 1994, 447-452.

25. MOCANU, G., NICHIFOR, M., Cationic amphiphilic dextran hydrogels with potential biomedical applications, Carbohyd.Polym., 99, 2014, 235-241.

26. STANCIU, M.C., NICHIFOR, M., Influence of dextran hydrogel characteristics on adsorption capacity for anionic dyes, Carbohyd. Polym., 199, 2018, 75-83.

27. STANCIU, M.C., NICHIFOR, M., Adsorption of anionic dyes on a cationic amphiphilic dextran hydrogel: equilibrium, kinetic, and thermodynamic studies, Colloid Polym. Sci., 297, 2019, 45-57.

28. NICHIFOR, M., STANCIU, M.C., SIMIONESCU, B.C., New cationic hydrophilic and amphiphilic polysaccharides synthesized by one pot procedure, Carbohyd. Polym., 82, 2010, 965-975.

29. FINI, A., FAZIO, G., RODA, A., BELLINI, A.M., MENCINI, E., GUARNERI, M., Basic cholane derivatives. XI: Comparison between acid and basic derivatives, J. Pharm. Sci., 81, 1992, 726-730.

30. FOO, K.Y., HAMEED, B.H., Insights into the modeling of adsorption isotherm systems, Chem. Eng. J., 156, 2010, 2-10.

31. LIU, C., HAO, J., WU, Z., Phase behavior and rheological properties of salt-free catanionic surfactant mixtures in the presence of bile acids, J. Phys. Chem. B, 114 (30), 2010, 9795-9804.

32. LANGMUIR, I., The constitution and fundamental properties of solids and liquids. Part I. Solids, $J$. Am. Chem. Soc., 38, 1916, 2221-2295.

33. FREUNDLICH, H.M.F., Over the adsorption in solution, J. Phys. Chem., 57, 1906, 1100-1107.

34. DUBININ, M.M., ZAVERINA, E.D., RADUSHKEVICH, L.V., Sorption and structure of active carbons, J. Phys. Chem., 1947, 21, 1351-1362. 
35. GUNAY, A., ARSLANKAYA, E., TOSUN, I., Lead removal from aqueous solution by natural and pretreated clinoptilolite: adsorption equilibrium and kinetics, J. Hazard. Mater., 146, 2007, 362-371.

36. DABROWSKI, A., Adsorption-from theory to practice, Adv. Colloid Interface Sci., 93, 2001, 135224.

37. TEMKIN, M.I., PYZHEV, V., Kinetics of ammonia synthesis on promoted iron catalyst, Acta Phys. Chim. USSR, 12, 1940, 327-356.

38. TEMKIN, M.I., Adsorption equilibrium and the kinetics of processes on non-homogeneous surfaces and in the interaction between adsorbed molecules, Zhurnal Fizicheskoi Khimii, 15, 1941, 296-332.

39. WANGA, X., JING, S., QIU, X., ZHAO, S., LIU, Y., TAN, Y., Novel bile acid sequestrant: A biodegradable hydrogel based on amphiphilic allylamine copolymer, Chem. Eng. J., 304, 2016, 493502.

40. SHEN, J., YANG, X., SUN, X., GONG, W., MA, Y., LIU, L., YAO, J., Amino-functionalized cellulose: a novel and high-efficiency scavenger for sodium cholate sorption, Cellulose, 27, 2020, 40194028.

41. ZHU, X., WEN, Y., WANG, L., LI, C., CHENG, D., ZHANG, H., NI, Y., Binding of Sodium Cholate in-Vitro by Cationic Microfibrillated Cellulose, Ind. Eng. Chem. Res., 53, 2014, 18508-18513. 42. BUDNYAK, T.M., VLASOVA, N.N., GOLOVKOVA, L.P., SLABON, A., TERTYKHA, V.A., Bile acids adsorption by chitosan-fumed silica enterosorbent, Colloid Interface Sci. Commun., 32, 2019, 100194-100201.

43. RAINA, S., MUNGANTIWAR, A., HALDE, S., PANDITA, N., High-performance liquid chromatography method applied to investigate mechanism, kinetics, isotherm, and thermodynamics of bile acidadsorption onto bile acid sequestrants, Drug Dev. Ind. Pharm., 45(9), 2019, 1437-1443.

44. CHEN, X., Modeling of Experimental Adsorption Isotherm Data, Information, 6, 2015, 14-22.

45. ZHU, X., WENA, Y., CHENG, D., LI, C., ANA, X., NI, Y., Cationic amphiphilic microfibrillated cellulose (MFC) for potential use for bile acid sorption, Carbohyd. Polym., 132, 2015, 598-605.

46. MAATAR, W., ALILA, S., BOUFI, S., Cellulose based organogel as an adsorbent for dissolved organic compounds, Ind. Crops Prod., 49, 2013, 33- 42.

47. EUSTON, S.R., BAIRD, W.J., CAMPBELL, L., KUH, M., Competitive Adsorption of Di-hydroxy and Tri-hydroxy Bile Salts with Whey Protein and Casein in Oil-in-Water Emulsions, Biomacromolecules, 14, 2013, 1850-1858.

48. YANEZ, F., CHIANELlA, I., PILETSKY, S. A., CONCHEIRO, A., ALVAREZ-LORENZO, C., Computational modeling and molecular imprinting for the development of acrylic polymers with high affinity for bile salts, Anal. Chim.Acta, 659, 2010, 178-185.

49. WILLIAMS, C., GALLEY, W., BROWN, G.R., The dominant role of solvent in the sequestering of bile salts by hydrophobic cationic polymeric resins, Langmuir, 20, 2004, 4220-4225.

50. SYNYTSYA, A., FESSLOVÁ, L., MAROUNEK, M., ČOPÍKOVÁ, J., Sodium cholate sorption on N-octadecylpectinamide in comparison with Cholestyramine, Czech J. Food Sci., 25(1), 2007, 32-38.

51. MENDONÇA, P., MATOS, A. SOUSA, A., SERRA, A., SIMÕES, S., COELHO, J., Increasing the bile acid sequestration performance of cationic hydrogels by using an advanced/controlled polymerization technique, Pharm. Res., 34, 2017, 1934-1943.

52. MENDONÇA, P., MORENO, M., SERRA, A., SIMÕES, S., COELHO, J., Synthesis of tailor-made bile acid sequestrants by supplemental activator and reducing agent atom transfer radical polymerization, RSC Adv., 6, 2016, 52143-52154.

Manuscript received: 15.07 .2020 